\title{
RESEARCH
}

\section{Malaria in overseas labourers returning to China: an analysis of imported malaria in Jiangsu Province, 2001-2011}

Yaobao Liu ${ }^{1,2}$, Michelle S Hsiang ${ }^{3,4}$, Huayun Zhou' ${ }^{1}$, Weiming Wang ${ }^{1}$, Yuanyuan Cao ${ }^{1}$, Roly D Gosling ${ }^{3}$, Jun Cao ${ }^{\text {1* }}$ and Qi Gao ${ }^{1,2^{*}}$

\begin{abstract}
Background: While great success in malaria control has been achieved in China, imported malaria has become a major challenge in the context of malaria elimination. This retrospective study describes the epidemiological profile of imported malaria and identifies the at-risk population during the period of 2001-2011 in Jiangsu Province.

Methods: Data on imported malaria cases in Jiangsu Province from 2001 to 2011 were collected from the infectious disease surveillance system and case investigation reports. Epidemiological trends were described and correlations between trends in exported labour and malaria imported from other countries were explored.

Results: From 2001 to 2011, 918 malaria cases and six malaria deaths were due to malaria imported from other countries, accounting for $12.4 \%$ of all malaria cases and $100 \%$ of all malaria deaths. During this time period the annual number of indigenous cases decreased from 1,163 to 13 while the number of imported cases increased from 86 to 366. The relative proportion of cases imported from other countries versus other provinces also increased from $0.0 \%(0 / 86)$ to $97.0 \%(350 / 361)$. The most affected demographic groups were males (897 cases, 97.7\%) and adults (20-50 years old: 857 cases, 93.4\%). All 918 cases had a recent travel history to malaria-endemic areas and the main purpose for travel was overseas labour (848 cases, 92.4\%). The cases were mainly acquired from African countries (855 cases, 93.1\%). Plasmodium falciparum was the most common species (733 cases, 79.8\%). The increase in malaria cases imported from other countries was associated with the growth of investment to Africa from Jiangsu $\left(R^{2}=0.8057\right)$ and the increasing number of exported labourers to Africa from Jiangsu $\left(R^{2}=0.8863\right)$.

Conclusions: From 2001 to 2011 in Jiangsu Province, there was a consistent increase in the number of malaria cases imported from other countries while the number of locally acquired cases sharply declined. This trend may be ascribed to the increasing investment from China to Africa and the rising number of Chinese labourers working in Africa. Preventative efforts should be targeted to this high-risk group and the surveillance and response system should be strengthened to prevent local resurgence in Jiangsu.
\end{abstract}

Keywords: Imported malaria, Overseas labourer, Exported labourer, Investment, Jiangsu Province, China, Africa, Migrant

\footnotetext{
*Correspondence: caojuncn@hotmail.com; gaoqi54@hotmail.com

'Jiangsu Institute of Parasitic Diseases, Key Laboratory of Parasitic Disease

Control and Prevention (Ministry of Health), Jiangsu Provincial Key Laboratory

of Parasite Molecular Biology, Wuxi, Jiangsu, People's Republic of China

${ }^{2}$ Medical College of Soochow University, Suzhou, People's Republic of China

Full list of author information is available at the end of the article
} 


\section{Background}

Malaria remains one of the major public health problems in the world. There are more than 100 malaria-endemic countries and almost one million deaths annually. The main endemic areas are sub-Saharan Africa, South America, the Pacific islands and Southeast Asian countries [1]. Due to global economic integration, large numbers of people travel to malaria-endemic countries for trade, tourism, labour and other purposes. Subsequently, importation of malaria from highly malariaendemic areas into lower or non-endemic countries is inevitable [2,3]. Approximately 125 million international travellers visit malaria-endemic countries yearly and over 10,000 cases are reported after returning home, according to the World Health Organization [4]. This situation makes malaria not only a threat to non-immune travellers, but also among local populations where those travellers live. For countries or areas that are near to or have already achieved elimination, imported malaria is a risk for resurgence or re-introduction of malaria.

Jiangsu Province is located in eastern China and had an estimated total population of 79 million people in 2011 [5]. The main malaria vectors are Anopheles sinensis with Anopheles anthropophagus [6]. Historically, malaria transmission was unstable and prone to large outbreaks. There were two peak epidemic periods in the 1960s and 1970s during which time about 10 million malaria cases were reported each year and the annual incidence was as high as 250/1,000 population. Plasmodium vivax, Plasmodium falciparum and Plasmodium malarie were endemic in Jiangsu, with the dominant species being $P$. vivax. Indigenous falciparum malaria was successfully eliminated in 1988 [7]. Indigenous vivax malaria in Jiangsu has been effectively controlled through comprehensive implementation of effective interventions and only 13 indigenous vivax cases were reported in 2011 [8]. In the context of the national malaria elimination programme, which was launched in 2010 and aims to achieve malaria elimination nationwide in China by 2020, Jiangsu province aims to interrupt local malaria transmission by $2015[9,10]$.

In recent years, there has been a rise in imported malaria in Jiangsu Province, providing a threat to elimination goals. In order to address this new challenge, a better understanding of imported malaria is needed. In this study, the epidemiological profile and trends of imported malaria in Jiangsu province from 2001-2011 are described.

\section{Methods}

\section{Study design and data collection}

Utilizing routine surveillance data from the China Centres for Disease Control and Prevention (CDC), a retrospective analysis of imported malaria in Jiangsu Province from 2001 to 2011 was carried out. All malaria cases were diagnosed and treated according to the national policy. Laboratory confirmed cases were diagnosed by microscopy. All positive slides and $10 \%$ of negative slides are reviewed for confirmation by an expert microscopist at the provincial laboratory. Non-laboratory confirmed cases, including species classification of these cases, were diagnosed according to symptoms, response to therapy, any previous diagnosis of malaria, and predominate species in the geographic origin of infection.

Monthly case reports were collected through the China Information System for Disease Control and Prevention (CISDCP), the national internet-based disease reporting system. More detailed demographic and clinical data, as well as travel history, were obtained from follow-up case investigations. Based on Technical Scheme of China Malaria Elimination [11], cases were classified by local staff as indigenous (acquired within the province), imported from other provinces (travel within the previous month to another district in China with local cases reported), or imported from other countries (travel within the previous month to a malaria-endemic country). Otherwise, the case was classified as local. When the source was unclear, the infection origin was determined by a provincial or national expert team.

Annual data on investment to Africa, and the number of labourers exported from Jiangsu to Africa were collected from the Jiangsu statistic yearbook [5] and confirmed by the Department of Commerce of Jiangsu Province.

\section{Data management and analysis}

Data were double entered into Microsoft Excel 2007 and then imported into SPSS17.0 to conduct the analysis. Characteristics of imported malaria were described according to geographical and temporal distribution, age and gender composition, travel purpose, country from where the infection was acquired, and Plasmodium species.

The trend lines for the malaria situation were generated by Moving Average (MA) method of Microsoft Excel 2007. The associations between the annual number of cases imported from other countries and annual number of exported labourers to Africa as well as annual investment to Africa from Jiangsu Province were analysed using linear regression analysis.

\section{Ethical considerations}

The study was approved by the Institutional Review Board of Jiangsu Institute of Parasitic Diseases (IRB00004221), Wuxi, China.

\section{Results}

Epidemiologic profile of malaria in Jiangsu Province from 2001 to 2011

Over the 11 years from 2001 to 2011, a total of 7,421 malaria cases were reported in Jiangsu Province. Most of 


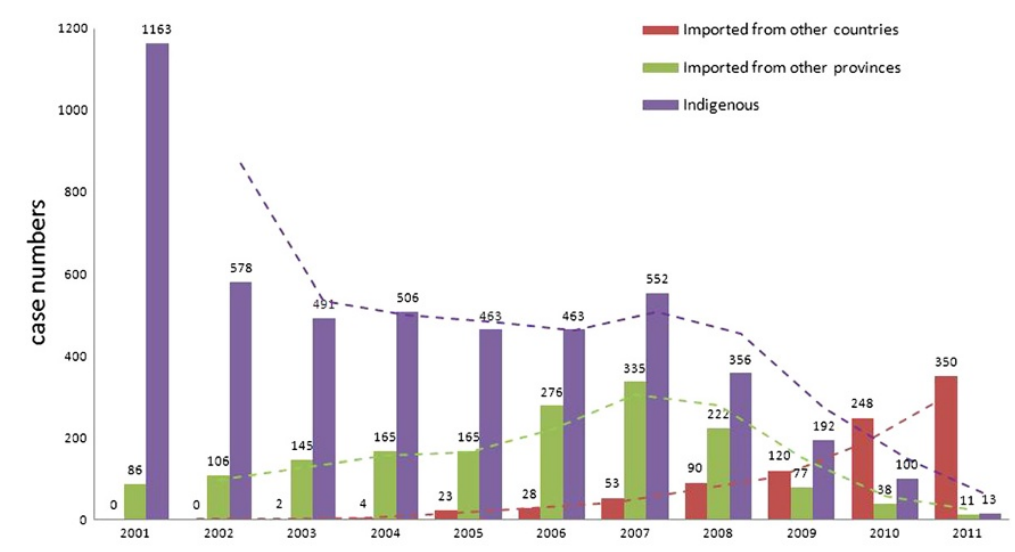

Figure 1 Malaria situation in Jiangsu Province, 2001-2011. The dashed lines and columns of different colours show the change trend of cases imported from other countries (red), cases imported from other provinces (green) and indigenous cases (blue), respectively.

the cases were classified as indigenous $(65.7 \%$, or 4,877 cases); $21.9 \%$ (1,626 cases) were imported from other provinces of China and 12.4\% (918 cases) were imported from other countries.

The annual number of indigenous cases sharply declined from 2000 to 2001, after which it was relatively stable, and then declined steadily after 2007. Imported cases from other provinces increased from 2001 to 2007 then declined steadily afterwards. The annual number of cases imported from other countries increased dramatically over the study period, exceeding the number of cases imported from other provinces in 2009, and exceeding the number of indigenous cases in 2010 (Figure 1). The relative proportion of cases imported from other countries versus other provinces increased from $0.0 \%(0 / 86)$ in 2001 to $97.0 \%$ (350/361) in 2011.

\section{Demographic characteristics of malaria cases imported from other countries}

Of the 918 malaria cases imported from other countries, 857 cases $(93.4 \%)$ were 20 to 50 years of age and the median age was 40 years (range: 11 to 69). Most cases occurred in males (897 cases, 97.7\%) (Figure 2). Chinese citizens accounted for 898 cases $(97.8 \%)$ and 20 cases

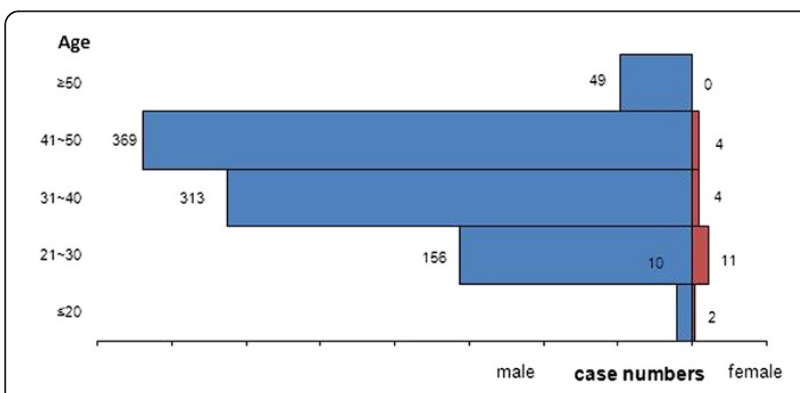

Figure 2 Imported cases from other countries, by age and sex.
(2.2\%) were in foreigners. The main purpose for travel was labour (848 cases, 92.4\%) (Figure 3).

\section{Clinical and laboratory characteristics of malaria cases imported from other countries}

Plasmodium falciparum was the dominant species accounting for 754 cases (82.1\%). Plasmodium vivax accounted for 128 cases (13.9\%), P. ovale 14 cases (1.5\%), P. malariae seven cases $(0.7 \%)$, and 15 (1.6\%) were not classified by species. Laboratory confirmation occurred in 815 cases (88.8\%) and 103 cases (11.2\%) were diagnosed clinically. Plasmodium falciparum diagnoses were more likely to be laboratory confirmed $(687 / 754,91 \%)$ than $P$. vivax cases $(101 / 128,78.9 \%)$. There were six deaths $(0.7 \%)$ all due to P. falciparum.

Demographic and clinical details from malaria deaths are shown in Table 1. All malaria deaths occurred in men aged 29 to 49 years returning from overseas labour in Africa. Median time intervals were as follows: from arrival in China to symptom onset was five days (range: -8-11), from symptom onset to first health facility visit was one day (range: $0-8$ ), from first health facility visit to malaria diagnosis was four days (range: $2-8$ ), and from symptom onset to malaria diagnosis was 4.5 days (range: $2-12$ ).

\section{Temporal and geographic characteristics of malaria cases} imported from other countries

Monthly reports of malaria cases imported from other countries showed no temporal pattern. In comparison, both indigenous cases and cases imported from other provinces of China peaked during the summer seasons (Figure 4).

All 13 prefectures of Jiangsu Province reported malaria cases imported from other countries though cases were concentrated in Yangzhou (171 cases, 18.6\%), Nantong (150 cases, 16.3\%) and Huai'an (110 cases, 12.0\%) (Figure 5). 


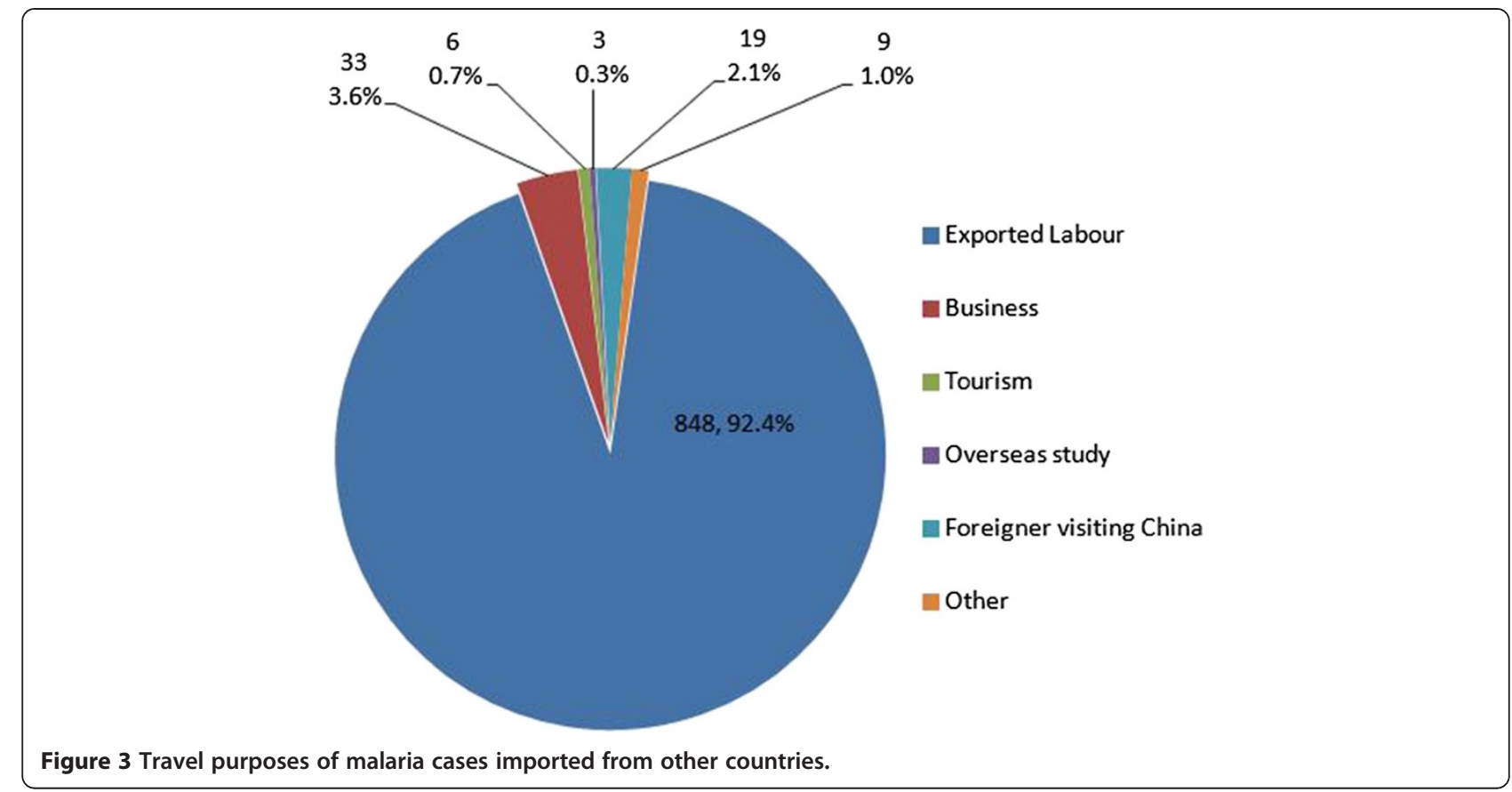

Most cases were acquired from Africa (855/918, 93.1\%), with the top three countries from where malaria was imported being Angola (245 cases), Nigeria (219 cases) and Equatorial Guinea (146 cases). By species, most cases were also from Africa: P. falciparum cases (733/754, 97.2\%), P. $\operatorname{vivax}(88 / 128,68.8 \%)$, P. ovale $(14 / 14,100 \%)$ and P. malariae $(7 / 7,100 \%)$. The region with the second largest number of imported cases was Southeast Asia (32/918, 3.5\%). These cases accounted for 24.2\% (31/128) of all P. vivax cases (Table 2).

Increasing malaria cases imported from other countries associated with investment and labourers exported to Africa from Jiangsu Province

Investment to African countries from Jiangsu Province increased over the study period and was related to the annual number of cases imported from other countries,
$\mathrm{R}^{2}=0.8057$. The annual number of labourers exported from Jiangsu to Africa also increased over the study period and this trend corresponded with the increase in cases imported from other countries, $R^{2}=0.8863$ (Figure 6).

\section{Discussion}

With globalization and increased international movement, imported malaria has become an important public health issue. For countries that are approaching or have achieved elimination, imported malaria is a risk for resurgence or re-introduction [12]. This study reviewed the imported malaria situation in Jiangsu, a province of China where the malaria burden has decreased considerably and elimination is now the goal. Focusing on the 11-year period from 2001 to 2011, the annual number of indigenous cases in Jiangsu declined dramatically. The

Table 1 Clinical and demographic details of malaria deaths

\begin{tabular}{|c|c|c|c|c|c|c|c|c|c|}
\hline \multirow[b]{2}{*}{$\begin{array}{c}\text { Case } \\
\text { no }\end{array}$} & \multirow[b]{2}{*}{ Year } & \multirow[b]{2}{*}{ Prefecture } & \multirow[b]{2}{*}{$\begin{array}{c}\text { Age } \\
\text { (years) }\end{array}$} & \multirow[b]{2}{*}{ Gender } & \multirow[b]{2}{*}{$\begin{array}{l}\text { Origin } \\
\text { country }\end{array}$} & \multicolumn{4}{|c|}{ Time intervals (days) } \\
\hline & & & & & & $\begin{array}{c}\text { Arrival in China } \\
\text { to symptom } \\
\text { onset }\end{array}$ & $\begin{array}{l}\text { Symptom onset } \\
\text { to first health } \\
\text { facility visit }\end{array}$ & $\begin{array}{c}\text { First health facility } \\
\text { visit to malaria } \\
\text { diagnosis }\end{array}$ & $\begin{array}{l}\text { Symptom onset } \\
\text { to malaria } \\
\text { diagnosis }\end{array}$ \\
\hline 1 & 2004 & Yangzhou & 36 & Male & Congo (Brazzaville) & 3 & 3 & 8 & 11 \\
\hline 2 & 2009 & Suqian & 49 & Male & Angola & 7 & 0 & 4 & 4 \\
\hline 3 & 2010 & Huaian & 29 & Male & Angola & 11 & 2 & 2 & 4 \\
\hline 4 & 2011 & Lianyungang & 32 & Male & Ghana & $-8^{a}$ & 8 & 4 & 12 \\
\hline 5 & 2011 & Nanjing & 37 & Male & Mozambique & 2 & 0 & 5 & 5 \\
\hline 6 & 2011 & Taizhou & 49 & Male & Equatorial Guinea & 11 & 0 & 2 & 2 \\
\hline
\end{tabular}

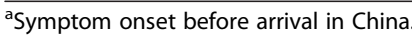




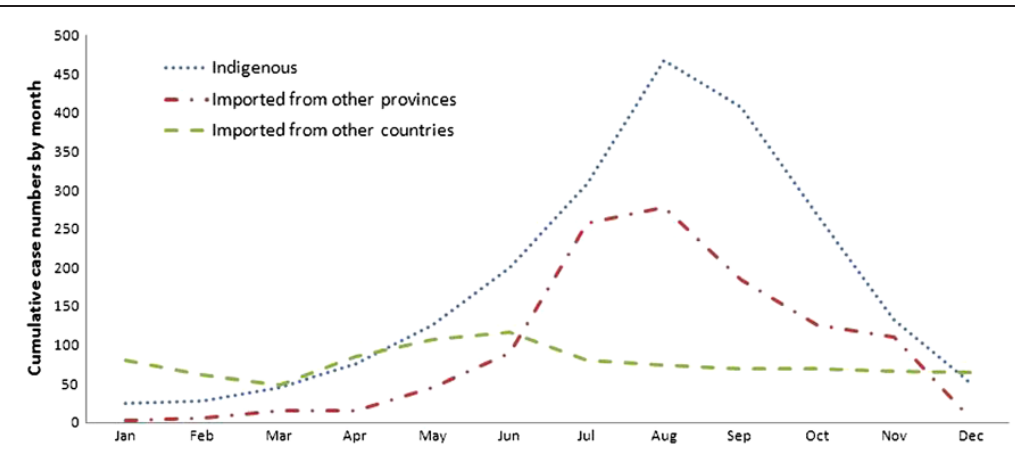

Figure 4 Monthly distributions of malaria cases in Jiangsu Province, 2001-2011.

annual number of cases imported from other provinces showed a similar trend to the indigenous cases reflecting the decrease in malaria in other parts of China [13]. However, there was a consistent increase in the number of malaria cases imported from other countries into Jiangsu Province.
Most imported cases were due to $P$. falciparum, the species most commonly associated with severe disease and death. Prompt diagnosis and appropriate treatment are critical [14]. However, the diagnosis is frequently missed or delayed. Of 309 falciparum cases in 2011, six cases were diagnosed more than 30 days after the first

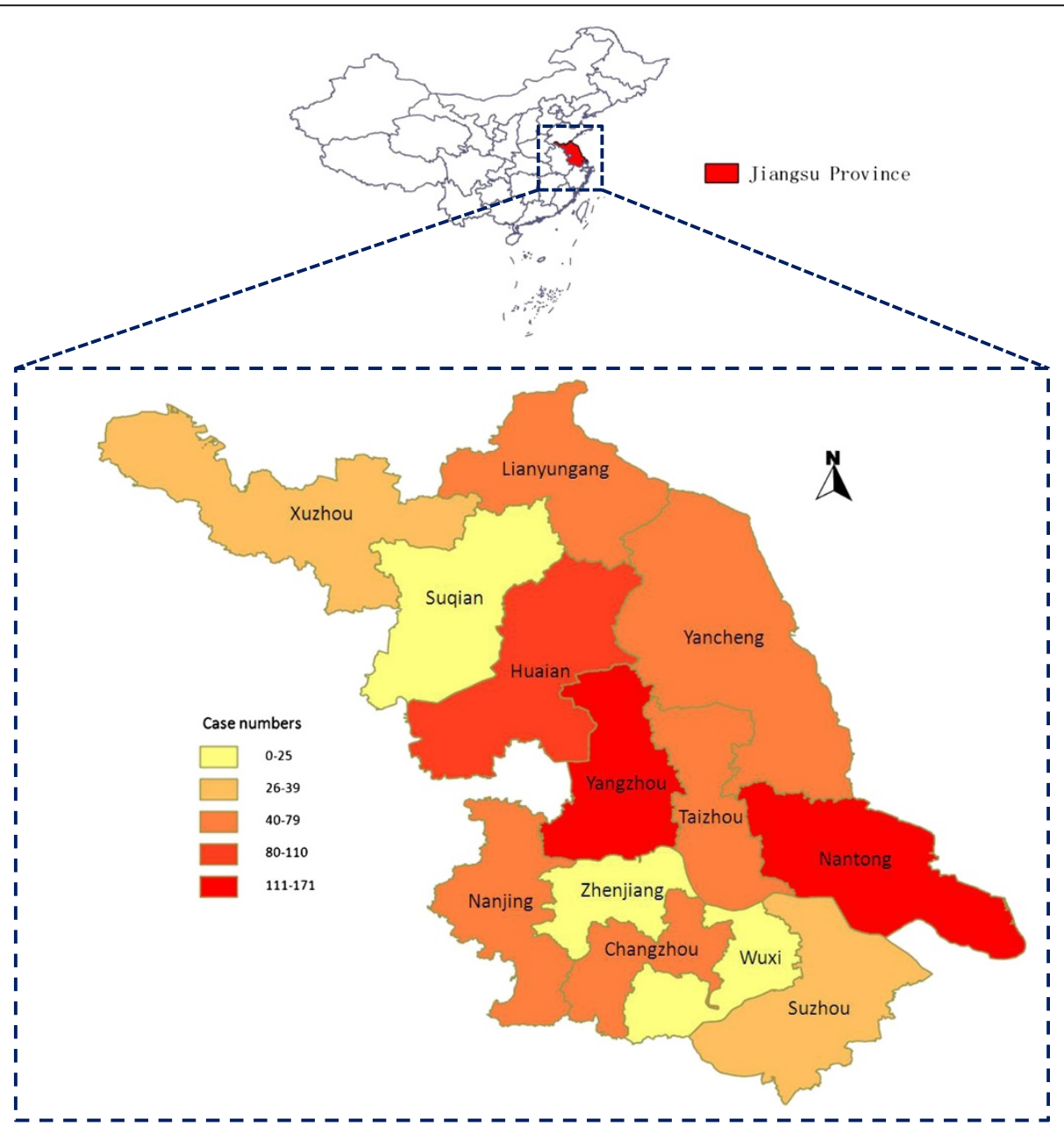

Figure 5 Distribution of imported malaria cases from other countries, 2001-2011. Case numbers are marked on the map by 13 prefectures of Jiangsu Province. 
Table 2 Malaria imported from other countries, by species and country

\begin{tabular}{|c|c|c|c|c|c|c|}
\hline \multirow[t]{2}{*}{ Origin country } & \multicolumn{5}{|c|}{ Species } & \multirow{2}{*}{$\begin{array}{c}\text { Total } \\
n=918\end{array}$} \\
\hline & P. falciparum $n=754$ & $P$. vivax $n=128$ & P. ovale $n=14$ & P. malariae $\mathrm{n}=7$ & Unclassified $n=15$ & \\
\hline Africa & 733 (97.2\%) & $88(68.8 \%)$ & $14(100 \%)$ & $7(100 \%)$ & $13(86.7 \%)$ & $855(93.1 \%)$ \\
\hline Angola & 219 & 17 & 1 & 3 & 5 & 245 \\
\hline Nigeria & 185 & 27 & 6 & 0 & 1 & 219 \\
\hline Equatorial Guinea & 130 & 10 & 5 & 0 & 1 & 146 \\
\hline Congo (Brazzaville) & 21 & 1 & 0 & 2 & 0 & 24 \\
\hline Ghana & 19 & 3 & 0 & 0 & 0 & 22 \\
\hline Gabon & 19 & 1 & 0 & 1 & 0 & 21 \\
\hline Madagascar & 15 & 0 & 0 & 0 & 2 & 17 \\
\hline Congo (Kinshasa) & 12 & 4 & 0 & 0 & 1 & 17 \\
\hline Mozambique & 14 & 1 & 1 & 0 & 0 & 16 \\
\hline Sudan & 13 & 3 & 0 & 0 & 0 & 16 \\
\hline Niger & 10 & 3 & 0 & 0 & 0 & 13 \\
\hline Guinea & 11 & 0 & 0 & 0 & 0 & 11 \\
\hline Liberia & 4 & 5 & 0 & 0 & 0 & 9 \\
\hline Uganda & 8 & 0 & 0 & 0 & 0 & 8 \\
\hline South Africa & 4 & 2 & 0 & 0 & 1 & 7 \\
\hline Togo & 5 & 0 & 0 & 0 & 0 & 5 \\
\hline Malawi & 3 & 1 & 0 & 1 & 0 & 5 \\
\hline Mali & 4 & 0 & 0 & 0 & 0 & 4 \\
\hline Sierra Leone & 4 & 0 & 0 & 0 & 0 & 4 \\
\hline Senegal & 4 & 0 & 0 & 0 & 0 & 4 \\
\hline Cameroon & 4 & 0 & 0 & 0 & 0 & 4 \\
\hline Côte d'Ivoire & 2 & 1 & 1 & 0 & 0 & 4 \\
\hline Tanzania & 3 & 0 & 0 & 0 & 0 & 3 \\
\hline Burkina Faso & 2 & 0 & 0 & 0 & 0 & 2 \\
\hline Chad & 2 & 0 & 0 & 0 & 0 & 2 \\
\hline Namibia & 1 & 0 & 0 & 0 & 0 & 1 \\
\hline Rwanda & 1 & 0 & 0 & 0 & 0 & 1 \\
\hline Kenya & 1 & 0 & 0 & 0 & 0 & 1 \\
\hline Zambia & 1 & 0 & 0 & 0 & 0 & 1 \\
\hline Ethiopia & 0 & 1 & 0 & 0 & 0 & 1 \\
\hline Unclear Africa & 12 & 8 & 0 & 0 & 2 & 22 \\
\hline South Asia & $0(0.0 \%)$ & $31(24.2 \%)$ & $0(0.0 \%)$ & $0(0.0 \%)$ & $1(6.7 \%)$ & $32(3.5 \%)$ \\
\hline India & 0 & 16 & 0 & 0 & 1 & 17 \\
\hline Pakistan & 0 & 15 & 0 & 0 & 0 & 15 \\
\hline Southeast Asia & $6(0.8 \%)$ & $6(4.7 \%)$ & $0(0.0 \%)$ & $0(0.0 \%)$ & $1(6.7 \%)$ & $13(1.4 \%)$ \\
\hline Myanmar & 4 & 3 & 0 & 0 & 0 & 7 \\
\hline Indonesia & 0 & 2 & 0 & 0 & 0 & 2 \\
\hline Laos & 2 & 0 & 0 & 0 & 0 & 2 \\
\hline Cambodia & 0 & 1 & 0 & 0 & 0 & 1 \\
\hline Thailand & 0 & 0 & 0 & 0 & 1 & 1 \\
\hline Oceana & $4(0.5 \%)$ & $1(0.8 \%)$ & $0(0.0 \%)$ & $0(0.0 \%)$ & $0(0.0 \%)$ & $5(0.5 \%)$ \\
\hline Papua New Guinea & 4 & 1 & 0 & 0 & 0 & 5 \\
\hline
\end{tabular}


Table 2 Malaria imported from other countries, by species and country (Continued)

\begin{tabular}{|c|c|c|c|c|c|c|}
\hline Latin America & $0(0.0 \%)$ & $1(0.8 \%)$ & $0(0.0 \%)$ & $0(0.0 \%)$ & $0(0.0 \%)$ & $1(0.1 \%)$ \\
\hline Bolivia & 0 & 1 & 0 & 0 & 0 & 1 \\
\hline Unknown & 11 (1.5\%) & 1 (0.8\%) & $0(0.0 \%)$ & $0(0.0 \%)$ & $0(0.0 \%)$ & 12 (1.3\%) \\
\hline
\end{tabular}

symptoms of the malaria clinical attack and three patients died because of delayed anti-malarial treatment [8]. The rarity of $P$. falciparum and non-specific presentation pose challenges to health care workers in non-endemic settings [15]. Indeed, in Jiangsu Province, most physicians and healthcare providers, especially those at the primary level, lack the awareness and skills to manage falciparum malaria [16].

The potential for local transmission from imported malaria is a challenge for malaria elimination [17-19]. Outbreaks from imported cases have been reported in many settings where transmission was previously interrupted [20-22]. In some situations, such as recently occurred in Greece, there has been re-establishment of local transmission [23]. Although P. falciparum was eliminated from Jiangsu Province more than 20 years [7] and $P$. vivax has almost been eliminated (there were no locally acquired cases of malaria reported in 2012 [24]), historically the province was a highly endemic area. The malaria vector is still widely distributed throughout the province and environmental conditions may be suitable for transmission [25]. The low immunity in the population is a further risk for outbreaks, as is the relaxation of surveillance, which often happens as burden declines. In 2000, after a long period of stable, low endemic malaria, there was a large outbreak of vivax malaria in Sihong County related to a resurgence of malaria in nearby Anhui Province [26]. Although cases imported from other countries have not led to secondary cases, careful surveillance and further research to prevent the reintroduction of malaria by imported cases from other countries is required.

Most of the malaria cases imported from other countries came from Africa. This is largely due to the increased travel to Africa by Chinese nationals. Since the 2000 Forum on China-Africa Cooperation (FOCAC), there has been increased investment and foreign aid from China to Africa. In this context, investment from Jiangsu Province to Africa has greatly increased in recent years. In particular, exported labour for construction has increased as more companies are supporting infrastructure development [27]. The study showed that increased investment and increased number of exported labourers to Africa from Jiangsu is closely related to the increased number of cases imported from other countries during 2001 to 2011. Although the data on the number of overseas labourers returning to Jiangsu from Africa each year was not able to be obtained, it is expected that the trends would be similar to that of Chinese labourers going to Africa.

The risk of acquiring malaria varies amongst travellers [28]. In Jiangsu Province, malaria imported from other countries mostly occurs in adult males returning from overseas labour. In other malaria elimination settings, adult males have also been found to be the new highrisk group, compared to higher endemic settings where young children and pregnant women are the highest risk group for mortality and morbidity [29]. Labourers are susceptible for several reasons. First, they usually work

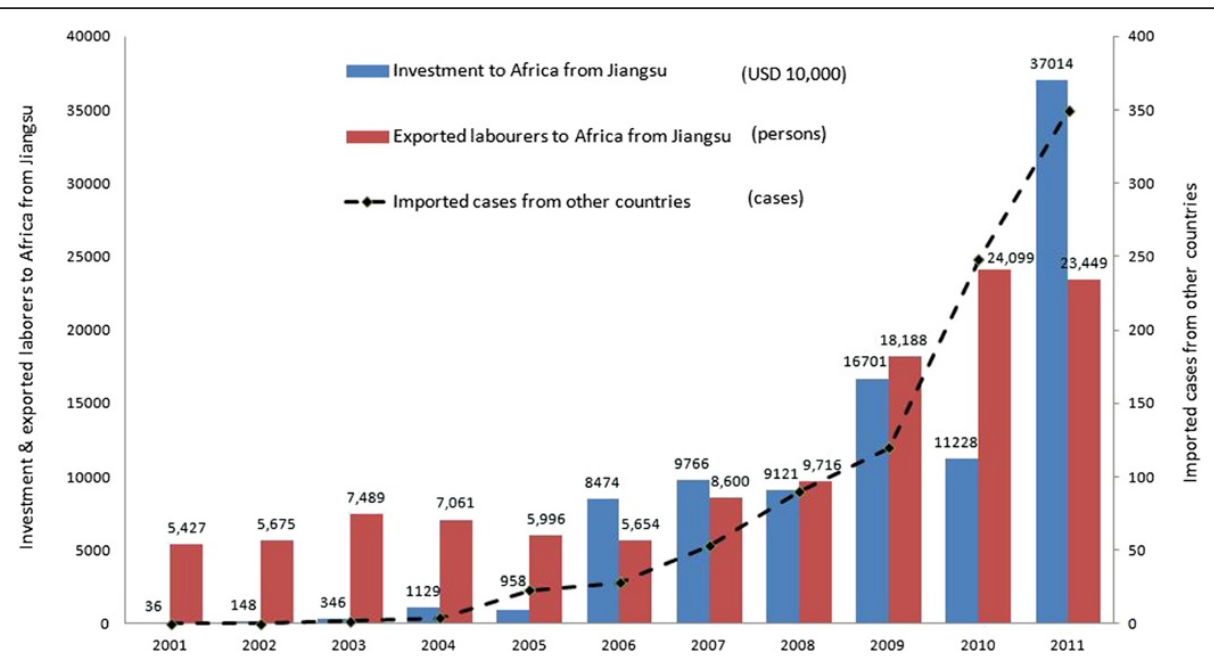

Figure 6 The investment and labourers exported to Africa from Jiangsu Province, 2001-2011. Annual number of imported malaria cases from other countries associated with the investment and labourers exported to Africa from Jiangsu Province. 
outdoors on construction sites and live in poor housing conditions, putting them at high risk for mosquito bites. Second, labourers generally lack immunity to malaria, especially to $P$. falciparum. Third, exported labourers are generally poorly educated and lack awareness of risks of malaria and personal protection [30].

The majority of labourers are exported through labourer service or construction companies. These companies should be targeted for the development of prevention programmes, such as in improved housing, health education and prophylaxis. Programmes could also be targeted geographically. $46.9 \%$ of cases imported from other countries occurred in three prefectures: Yangzhou, Nantong and Huai'an (Figure 4). Nantong has a large construction industry [31]. In Yangzhou and Huai'an there are numerous intermediary companies offering labourer services. The CDC considered programmes that could be targeted temporally (e g, border screening during the holidays when Chinese nationals are returning home), but there was no seasonal pattern as has been reported in other settings [32].

Intersectorial cooperation between departments of health, education, security, commerce, travel, inspection, and quarantine can play an important role in the management of imported malaria. For example, the entryexit inspection and quarantine agencies can carry out malaria screening for febrile travellers and then inform the local CDC of positive malaria cases. Other departments can cooperate with local CDC to carry out health education for labourers and others travelling to malariaendemic countries.

\section{Conclusion}

Imported malaria showed an increasing trend from 2001 to 2011 and it has become a major challenge for malaria elimination in Jiangsu Province. The main reason for the increase is the large number of exported labourers to malaria-endemic areas of Africa. Preventative measures should be targeted to high-risk groups and strengthened surveillance and response is needed to prevent local introduction of malaria.

\section{Competing interests}

The authors declare that they have no competing interests.

\section{Authors' contributions}

YBL and JC conceived the study, YBL collected and analyzed the data and drafted the manuscript. MSH and RG contributed to data analysis and manuscript writing. HYZ contributed to the data interpretation and coordination. WMW contributed to data collection and interpretation. YYC contributed to data analysis and map drawing. JC and QG provided guidance and coordination throughout the entire process. All authors read and approved the final manuscript.

\section{Acknowledgements}

This work was supported by Jiangsu Province's Construction project (BM2009902), Jiangsu Province's Medical High Tech Platform (ZX201108) and the National S \& T Major Programme (2012ZX10004220). This investigation received financial support from TDR, the Special Programme for Research and Training in Tropical Diseases, co-sponsored by UNICEF, UNDP, the World Bank and WHO. We are grateful for the support from Asia Pacific Malaria Elimination Network (APMEN); YBL and JC were recipients of APMEN fellowship. We also thank Lin Zheng (Department of Commerce of Jiangsu Province) and Peng Zhen (Jiangsu Institute of Parasitic Diseases) for their support in collecting data on investment and exported labourers.

\section{Author details}

1 Jiangsu Institute of Parasitic Diseases, Key Laboratory of Parasitic Disease Control and Prevention (Ministry of Health), Jiangsu Provincial Key Laboratory of Parasite Molecular Biology, Wuxi, Jiangsu, People's Republic of China. ${ }^{2}$ Medical College of Soochow University, Suzhou, People's Republic of China. ${ }^{3}$ Malaria Elimination Initiative, Global Health Group, University of California, San Francisco (UCSF), San Francisco, CA, USA. ${ }^{4}$ Department of Pediatrics, UCSF Benioff Children's Hospital, UCSF, San Francisco, CA, USA.

Received: 2 November 2013 Accepted: 21 January 2014 Published: 25 January 2014

\section{References}

1. WHO: World Malaria Report. Geneva: World Health Organization; 2012.

2. Askling HH, Nilsson J, Tegnell A, Janzon R, Ekdahl K: Malaria risk in travelers. Emerg Infect Dis 2005, 11:436-441.

3. Genton B, D'Acremont V: Malaria prevention in travelers. Infect Dis Clin North Am 2012, 26:637-654.

4. WHO: International Travel and Health 2011th edition. Geneva: World Health Organization; 2011

5. Jiangsu Bureau of Statistics: Jiangsu statistic yearbook 2003-2012 [in Chinese]. China: Jiangsu; 2013.

6. Zhou HY, Cao J, Wang WM, Li JL, Gu YP, Zhu GD, Gao Q: [Epidemic and control of malaria in Jiangsu Province] (in Chinese). Zhongguo Xue Xi Chong Bing Fang Zhi Za Zhi 2009, 21:503-506.

7. Zhang XP, Gao Q, Wu ZX, Zhao YJ, Ge J: [Investigation of falciparum malaria control in Jiangsu province] (in Chinese). Zhongguo Ji Sheng Chong Xue Yu Ji Sheng Chong Bing Za Zhi 1996, 9:245-249.

8. Zhou HY, Cao J, Wang WM, Liu YB, CAO YY, Gao Q: [Epidemiological analysis of malaria situation in Jiangsu Province in 2011] (in Chinese). Zhongguo Xue Xi Chong Bing Fang Zhi Za Zhi 2013, 25:31-35.

9. Zhou SS, Wang Y, Xia ZG: [Malaria situation in the People's Republic of China in 2009] (in Chinese). Zhongguo Ji Sheng Chong Xue Yu Ji Sheng Chong Bing Za Zhi 2011, 29:1-3.

10. Action Plan of China Malaria Elimination (2010-2020) (in Chinese). [http://www.gov.cn/gzdt/att/att/site1/20100526/001e3741a2cc0d67233801.doc]

11. Technical Scheme of China Malaria Elimination 2011th edition (in Chinese). [http://www.chinacdc.cn/tzgg/201109/P020110906378403678170.doc]

12. Tatem AJ, Smith DL: International population movements and regional Plasmodium falciparum malaria elimination strategies. Proc Natl Acad Sci USA 2010, 107:12222-12227.

13. Yanan $L$, Liang $W$, Chengyi L: [Descriptive analysis of trends of malaria prevalence in China from 2006 to 2010] (in Chinese). Chin J Public Health 2013, 29:263-265.

14. WHO: Management of severe malaria: a practical handbook. Geneva: World Health Organization; 2012.

15. Taylor SM, Molyneux ME, Simel DL, Meshnick SR, Juliano JJ: Does this patient have malaria? JAMA 2010, 304:2048-2056.

16. Liu YB, Cao J, Zhou HY, Wang WM, Cao YY, Gao Q: [Analysis of overseas imported malaria situation and implication for control in Jiangsu Province, PR China] (in Chinese). Zhongguo Xue Xi Chong Bing Fang Zhi Za Zhi 2013, 25:44-47.

17. Anis $E$, Pener $H$, Goldmann $D$, Leventhal $A$ : The reemergence of malaria in Israel? Harefuah 2004, 143:815-819. 838, 837.

18. D'Ortenzio E, Sissoko D, Dehecq JS, Renault P, Filleul L: Malaria imported into Reunion Island: is there a risk of re-emergence of the disease? Trans R Soc Trop Med Hyg 2010, 104:251-254.

19. Galappaththy GN, Fernando SD, Abeyasinghe RR: Imported malaria: a possible threat to the elimination of malaria from Sri Lanka? Trop Med Int Health 2013, 18:761-768.

20. Kruger A, Rech A, Su XZ, Tannich E: Two cases of autochthonous Plasmodium falciparum malaria in Germany with evidence for local 
transmission by indigenous Anopheles plumbeus. Trop Med Int Health 2001, 6:983-985.

21. Limongi JE, Chaves KM, Paula MB, Costa FC, Silva Ade A, Lopes Ide S, Pajuaba Neto Ade A, Sales JM, Rodrigues F, Resende MA, Ferreira MS: Malaria outbreaks in a non-endemic area of Brazil, 2005. Rev Soc Bras Med Trop 2008, 41:232-237.

22. Zoller T, Naucke TJ, May J, Hoffmeister B, Flick H, Williams CJ, Frank C, Bergmann F, Suttorp N, Mockenhaupt FP: Malaria transmission in non-endemic areas: case report, review of the literature and implications for public health management. Malar J 2009, 8:71.

23. Danis K, Lenglet A, Tseroni M, Baka A, Tsiodras S, Bonovas S: Malaria in Greece: historical and current reflections on a re-emerging vector borne disease. Travel Med Infect Dis 2013, 11:8-14.

24. Jiangsu Institute of Parasitic Diseases: The report of malaria elimination in Jiangsu Province in 2012 [in Chinese]. China: Wuxi, Jiangsu; 2013.

25. Wang WM, Zhou HY, Cao J, Li JL, Zhu GD, Gu YP, Liu YB: [Survey on malaria vectors in Jiangsu Province, 2005-2009] (in Chinese). Zhongguo Xue Xi Chong Bing Fang Zhi Za Zhi 2011, 23:453-456.

26. She GZ, Hong P, Peng F, Wang WM: [Prevalence and control of malaria in Sihong County from 1997 to 2007] (in Chinese). Zhongguo Xue Xi Chong Bing Fang Zhi Za Zhi 2010, 22:84-86.

27. Liang M: [The present situation and prospect of trade and economic cooperation between China and Africa] (in Chinese). Int Eco Cooperation 2012, 11:27-31.

28. Schlagenhauf $\mathrm{P}$, Hommel M: Travellers' malaria-'one shoe does not fit all'. Malar J 2011, 10:129.

29. Cotter C, Sturrock HJ, Hsiang MS, Liu J, Phillips AA, Hwang J, Gueye CS, Fullman N, Gosling RD, Feachem RG: The changing epidemiology of malaria elimination: new strategies for new challenges. Lancet 2013, 382:900-911.

30. Zhang M, Liu Z, He H, Luo L, Wang S, Bu H, Zhou X: Knowledge, attitudes, and practices on malaria prevention among Chinese international travelers. J Travel Med 2011, 18:173-177.

31. Zhang $X Y$, Zhang XY, Ming FK: Investigation of Nantong construction industry foreign economic situation] (in Chinese). Constr Enterprise Manage 2010, 260:64-66.

32. Rivera-Matos IR, Atkins JT, Doerr CA, White AC Jr: Pediatric malaria in Houston, Texas. Am J Trop Med Hyg 1997, 57:560-563.

doi:10.1186/1475-2875-13-29

Cite this article as: Liu et al: Malaria in overseas labourers returning to China: an analysis of imported malaria in Jiangsu Province, 2001-2011. Malaria Journal 2014 13:29.

\section{Submit your next manuscript to BioMed Central and take full advantage of:}

- Convenient online submission

- Thorough peer review

- No space constraints or color figure charges

- Immediate publication on acceptance

- Inclusion in PubMed, CAS, Scopus and Google Scholar

- Research which is freely available for redistribution 